\section{Donor-Acceptor Substituted Polyenes: Orientation in Mono- and Multilayers**}

By Christoph Bubeck, Franz Effenberger*, Lukas Häußling, Dieter Neher, Claus-Peter Niesert, and Helmut Ringsdorf

Large molecules containing different chemical units whose interactions within the molecule result in new macroscopically observable effects, have become increasingly important. ${ }^{[1]}$ The organization of molecules of this type in ordered structures leads to functional molecular materials. ${ }^{[2]}$ Their use in molecular electronics ${ }^{[3]}$ requires that the units exhibit specific electronic properties. ${ }^{[4]}$

Recently, we reported on the intramolecular energy transfer through terminally substituted conjugated polyenes. ${ }^{[5]}$ An intramolecular electron transfer within donor-acceptor substituted polyenes can be achieved by introducing suitable terminal groups. ${ }^{[6]}$ by UV/vis spectroscopy and angle-dependent second harmonic generation $(\mathrm{SHG}) .^{[8]}$

In compounds $\mathbf{4}$, anthracene was chosen as the electron donor moiety for its selective excitability when linked to polyenes ${ }^{[5 \mathrm{c}]}$ and for its donor potential with respect to photoinduced electron transfer, ${ }^{[9]}$ Pyridinium acceptors were used not only for their high reduction potential but also because of their ionic nature rendering molecules 4 amphiphilic and thus self organizable into monolayers. The polyenyl-pyridinium salts 4 were obtained via Wittig and Horner reactions (Scheme 1). ${ }^{[10]}$

The UV/vis absorption spectra of $3 \mathbf{c}$ and $4 \mathbf{c}$ (Fig. 1) display absorption maxima at $256 \mathrm{~nm}$ corresponding to the excitation of the ${ }^{1} B_{b}$-state $\left(S_{0} \rightarrow S_{3}\right.$ transition) of anthracene. ${ }^{[5 c, 11]}$ The long-wavelength absorption is attributed to the pyridinyl-polyene excitation (polyene $S_{0} \rightarrow S_{2}$ band). The bathochromic shift of about $100 \mathrm{~nm}$ in the polyenyl-

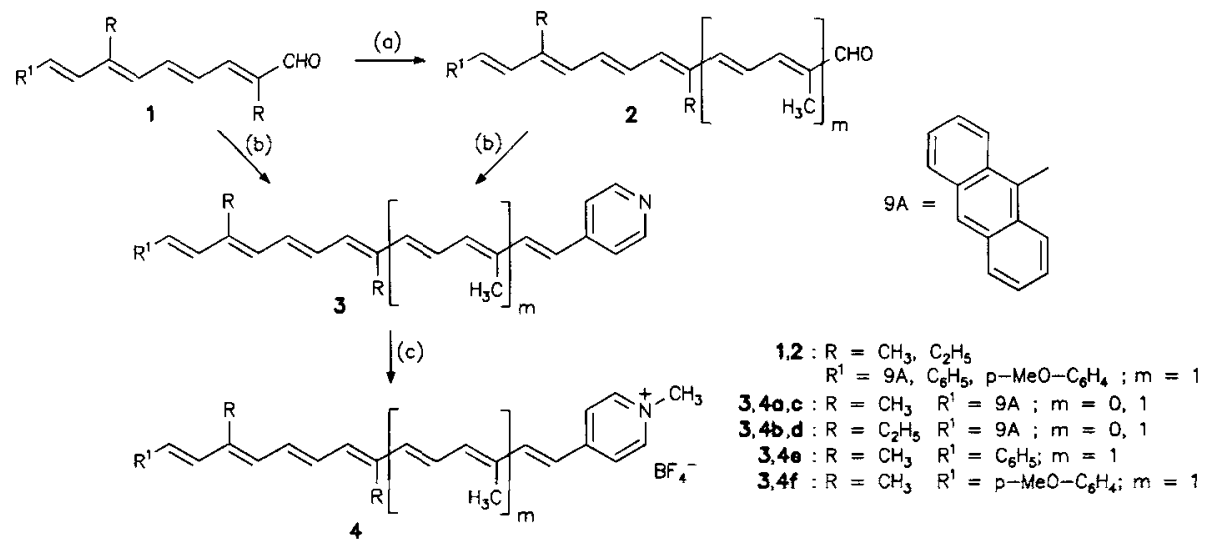

Scheme 1. 1: From 2,7-dimethyl- or 2,7diethyloctatrienedial $[10 \mathrm{~b}, 22]$. a) $(4,4-$ Dimethoxy-3-methyl-2-butenyl)triphenylphosphonium chloride $[23] / 1 / \mathrm{CH}_{3} \mathrm{OH} /$ $\mathrm{CH}_{2} \mathrm{Cl}_{2} ; \mathrm{CH}_{3} \mathrm{OH} / \mathrm{NaOCH}_{3}=1 \mathrm{~h} ; 1$ h stirring; chromatography on $\mathrm{SiO}_{2} / \mathrm{CH}_{2} \mathrm{Cl}_{2}$; recrystallization from toluene $/ \mathrm{CH}_{3} \mathrm{OH}$. b) 1 or $\mathbf{2} / 4-[$ (diphenylphosphinyl)methyl]pyridine [24]/18-crown-6/THF/NaH/2 h/room temperature; chromatography on $\mathrm{Al}_{2} \mathrm{O}_{3}$ $\mathrm{CH}_{2} \mathrm{Cl}_{2}$; recrystallization from $\mathrm{CH}_{2} \mathrm{Cl}_{2} /$ $\mathrm{CH}_{3} \mathrm{OH}$. c) Trimethyloxonium-tetrafluoroborate $/ \mathrm{CH}_{2} \mathrm{Cl}_{2}$ /solution of 3 in $\mathrm{CH}_{2} \mathrm{Cl}_{2} /$ $2 \mathrm{~h} /$ room temp.; recrystallization from acetone/diethylether. 4g: Analogous to 17-(9'anthryl)-2,6,11,15-tetramethylheptadecaoctaenal [22]. All compounds gave correct elementary analyses $(\mathbf{4 g}$ : correct molecular ion composition in mass spectrometry). The all-trans stereoisomerism of polyenes was confirmed by HPLC, ${ }^{1} \mathrm{H}-\mathrm{NMR}$, and UV/ vis spectroscopy.

In the present communication we describe phenyl- or anthryl-polyenyl-pyridinium salts 4 , their ability to form ordered monolayers on the water surface, the transfer of these monolayers onto solid supports by the Langmuir-Blodgett technique ${ }^{[7]}$ and the characterization of the resulting films

[*] Prof. F. Effenberger, C.-P. Niesert

Institut für Organische Chemie der Universität Stuttgart

Pfaffenwaldring 55, W-7000 Stuttgart 80 (FRG)

Dr. L. Häußling, Prof. H. Ringsdorf

Institut für Organische Chemie der Universität Mainz

J.J.-Becherweg 18-20, W-6500 Mainz (FRG)

Dr. C. Bubeck, Dr. D. Neher

Max-Planck-Institut für Polymerforschung

Ackermannweg 10, W-6500 Mainz (FRG)

[**] F. E. and C.-P. N. thank Dr. D. Möbius and G. Overbeck (MPI f. Biophysikalische Chemie, Göttingen) for their help in measuring reflection spectra and fruitful discussions. We thank Prof. G. Wegner, Mainz, for his interest in this work. This work was supported by the Deutsche Forschungsgemeinschaft (SFB 329). [AMC144] pyridinium compounds 4 compared to polyenyl-pyridines 3 is due to the enhanced charge-transfer character which results from the greater electron affinity of the pyridinium

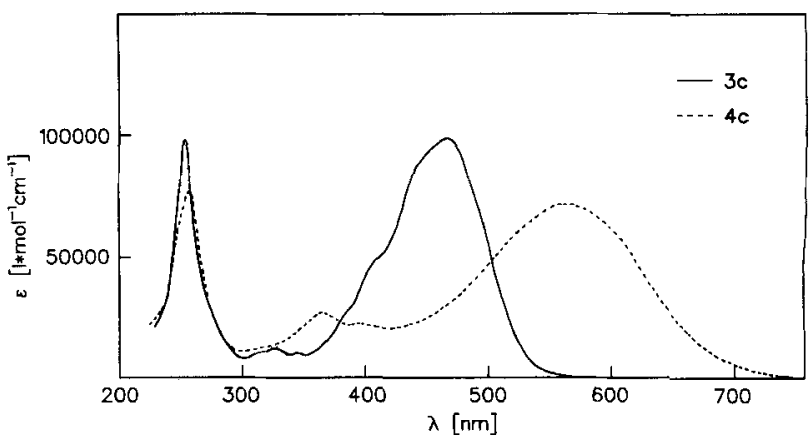

Fig. 1. UV/vis absorption spectra of compounds $4 \mathbf{c}$ and $3 \mathbf{c}$ in dichloromethane $\left(20^{\circ} \mathrm{C}, 4 \mathrm{c}: c=1.05 \cdot 10^{-5} \mathrm{M}, 3 \mathrm{c}: c=6.63 \cdot 10^{-6} \mathrm{M}\right)$ 
moiety. Compounds 4 show bathochromic shifts of $40-$ $50 \mathrm{~nm}$ in chlorinated hydrocarbons (solvatochromism).

The spreading of anthryl polyene amphiphiles 4 from $\mathrm{CH}_{2} \mathrm{Cl}_{2}$ solutions on a water surface revealed a considerable chain-length dependence of the monolayer formation due to the balance between the water solubility of the compounds with shorter chains and the tendency for aggregation of the compounds with longer chains. Even with the addition of polyelectrolytes (like polyacrylic acid) to the subphase ${ }^{[12]} \mathbf{4 a}$ and $\mathbf{4 b}$ did not give monolayers at air-water interfaces. The reduced water solubility of $\mathbf{4 c}$ and $\mathbf{4 d}$ allowed the formation of monolayers from these compounds (Fig. 2).

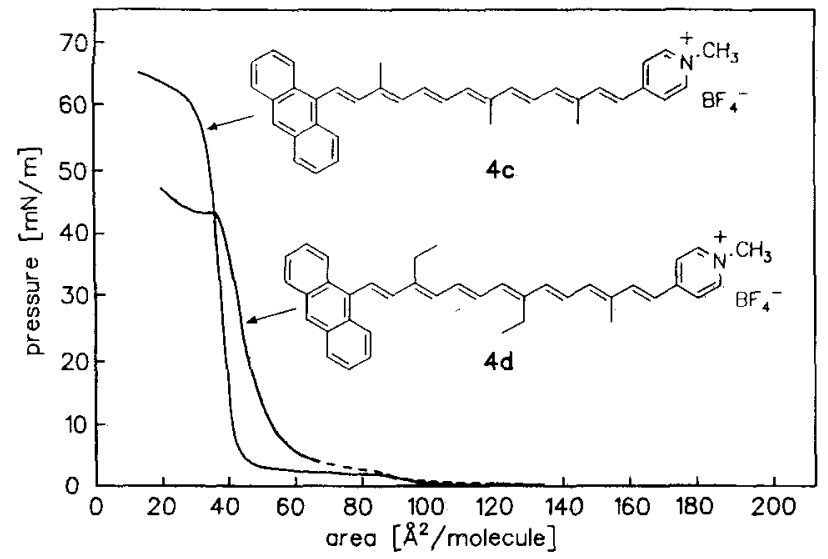

Fig. 2. Pressure-area diagrams of $4 \mathrm{c}$ and $4 \mathrm{~d}$ (Langmuir-measuring system. subphase water, $20^{\circ} \mathrm{C}$, rate of compression $13.3 \AA^{2} /$ molecule $\cdot \mathrm{min}$ ).

Ethyl substituents along the polyene chain as in $\mathbf{4} \mathbf{d}$ markedly influence the pressure-area isotherms. They give rise to less rigid monolayers as seen from a less steep slope in the solid analogous region, a more distinct collapse at diminished collapse pressure, and the easier transfer of the monolayers onto solid supports compared to $\mathbf{4 c}$. It is very interesting that there is a coexistence region of fluid and ordered phases for monolayers of both $\mathbf{4 c}$ and $\mathbf{4 d}$. However, the formation of domains ${ }^{[13]}$ in this region is accompanied by a noticeable water solubility as seen either at a reduced speed of compression or higher temperature of the aqueous subphase. The former resulted in a diminished surface pressure in the coexistence region while the latter additionally gave a smaller collapse area.

Although compounds $\mathbf{4 e}$ and $\mathbf{4 f}$ are of the same length as $4 \mathbf{c}, \mathbf{d}$ (but bear the phenyl instead of the anthryl moiety) they do not form stable monolayers. Even if sodium polystyrene sulfonate is added to the subphase in varying amounts $(0.5-$ $12.5 \mathrm{mg} / 1) \mathbf{4 f}$ did not give reproducible pressure-area isotherms.

The phase coexistence region is even more pronounced with $\mathbf{4 g}$ which is almost insoluble in water (Fig. 3). Despite being exposed to the same experimental conditions, different pressure-area isotherms were recorded for $\mathbf{4} \mathbf{g}$ which coincide in the region of monolayer collapse but differ markedly

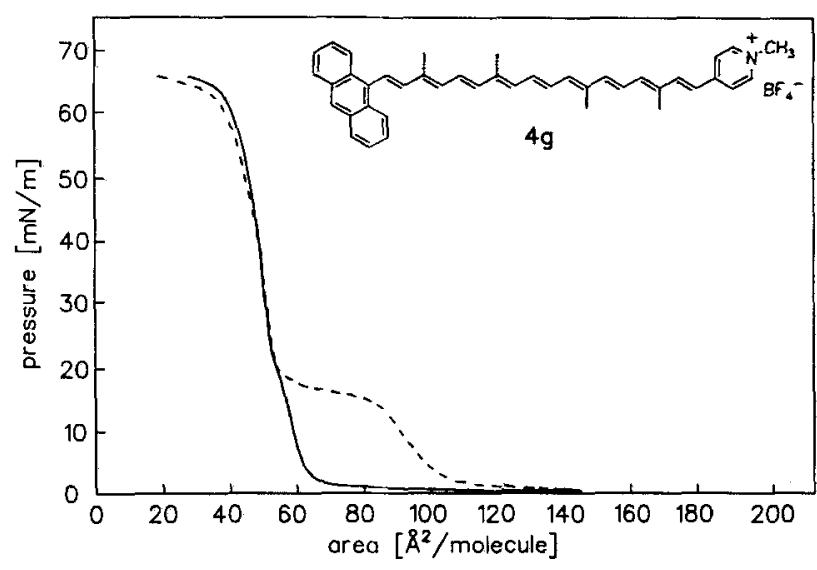

Fig. 3. Pressure-area diagrams of $4 \mathrm{~g}$ on pure water (Langmuir-measuring system, $20^{\circ} \mathrm{C}, 13 \AA^{2} /$ molecule $\cdot \min$ ). Despite of identical procedure each spreading gives a different isotherm in the pressure-range below $20 \mathrm{mN} / \mathrm{m}$ because of patches of aggregated $\mathbf{4 g}$.

in the phase coexistence region, where patches of aggregated $4 \mathrm{~g}$ are directly observable. A comparison of the data reveals that the area occupied by anthryl-polyenyl-compounds $\mathbf{4}$ is mainly governed by the anthryl group and by coulomb repulsion of the pyridinium ion (Table 1).

Table 1. Pressure-area data of $\mathbf{4 c}, \mathbf{d}$, and $\mathbf{g}$ and literature data of similar compounds 5,6 (Langmuir measuring system, subphase water, $20^{\circ} \mathrm{C}, 13.3 \AA^{2}$ / molecule $\min$ ).

\begin{tabular}{lllll}
\hline & $\begin{array}{l}\pi_{\mathrm{c}}[\mathrm{a}] \\
{[\mathrm{mN} / \mathrm{m}]}\end{array}$ & $\begin{array}{l}A_{\mathrm{c}}[\mathrm{b}] \\
{\left[\AA^{2} / \text { molecule }\right]}\end{array}$ & $\begin{array}{l}A_{20}[\mathrm{c}] \\
{\left[\AA^{2} / \text { molecule }\right]}\end{array}$ & $\begin{array}{l}A_{0}[\mathrm{~d}] \\
{\left[\AA^{2} / \text { molecule }\right]}\end{array}$ \\
\hline $\mathbf{4 c}$ & 48 & 35 & 39 & 42 \\
$\mathbf{4 d}$ & 36 & 41 & 45 & 49 \\
$\mathbf{4 g}$ & 42 & 50 & - & - \\
$\mathbf{5}[\mathrm{e}]$ & - & 28 & - & - \\
$\mathbf{6}[\mathrm{f}]$ & 53 & - & - & 38 \\
\hline
\end{tabular}

[a] Collapse pressure, determined from that point the pressure-area curve deviates from a straight line (precision $\pm 5 \mathrm{mN} / \mathrm{m}$ ). [b] Molecular area at collapse pressure (precision $\pm 2 \AA^{2} /$ molecule). [c] Molecular area at transfer pressure of $20 \mathrm{mN} / \mathrm{m}$. [d] Extrapolated molecular area at zero pressure. [e] Ethyl- $\beta$-apo$8^{\prime}$-carotenoate [25]. [f] 9-Anthrylnonaene acid [26].

Monolayers of $\mathbf{4 c}$ and $\mathbf{4 d}$ were transferable onto solid supports by the Langmuir-Blodgett technique. Using pure water as subphase, only two monolayers of $4 \mathrm{c}$ were transferable onto hydrophobic glass or quartz glass slides using $\mathrm{Y}$ type deposition ${ }^{[7]}$ with a transfer ratio equal to 1.0 . Upon further dipping, previously transferred LB film floated off.

The less rigid monolayers of $\mathbf{4} \mathbf{d}$ were transferred more easily than $4 \mathbf{c}$ and up to 30 monolayers were built up on hydrophobic substrates (glass, quartz glass). The transfer ratio was equal to 1.0 for the first double layer. For the second and the following dipping cycles it was approximately 0.6 for the downstroke and 1.0 for the upstroke.

In the UV/vis sprectra of LB films of $4 \mathrm{~d}$ the longest-wavelength band is broadened and slightly hypsochromically shifted compared to solutions in non-chlorinated solvents. A 
much larger hypsochromic shift of about $35 \mathrm{~nm}$ is found when aggregation is induced by addition of methanol/water to a solution of $4 \mathrm{c}$ in ethanol, a typical method of studying the effect of aggregation on the spectra of carotenoids. ${ }^{[4]}$

Because of the alignment of the transition dipole moment of the polyene $S_{0} \rightarrow S_{2}$ band parallel to the polyene axis, information on the orientation of the polyene molecules within the LB layers could be obtained even from linear UV/vis spectra recorded with perpendicular incidence of light. ${ }^{[15]}$ Thus, the absorptions of LB films of $\mathbf{4 c}, \mathbf{d}$ are in agreement with an isotropic distribution of molecular tilt angles.

Further information on the orientation of chromophores within non-centrosymmetric films could be obtained from angle-dependent second-harmonic generation (SHG). ${ }^{[16]}$ Large conjugated donor-acceptor substituted systems have large second-order polarizabilities ${ }^{[17]}$ and hence give effective second harmonic generation as demonstrated by calculation $^{[18]}$ and experiment ${ }^{[17]}$

Though the preparation of each of the LB films of $4 \mathrm{c}$ was carried out using an identical method and all films had the same linear UV/vis absorption, the results obtained for SHG for each monolayer differed markedly in susceptibilities $\chi^{[2]}$ and in the calculated tilt angles (Fig. 4). Obviously, the preparation of LB films from these stiff monolayers was not completely controllable.

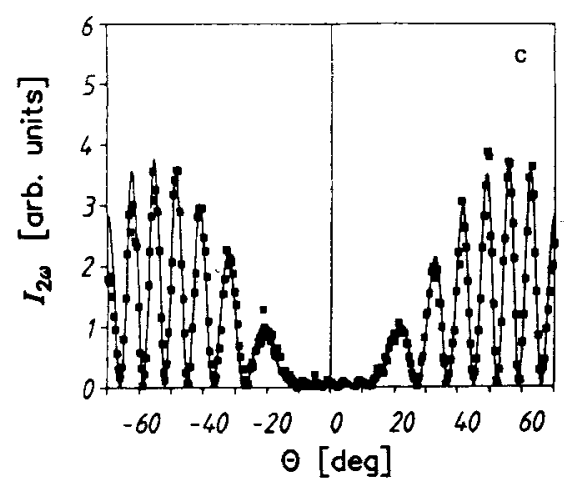

\begin{tabular}{|ccc|}
\hline & $\Phi\left[^{0}\right]$ & $\chi_{\xi \xi \xi}{ }^{(2)}\left[10^{-9}\right.$ esu $]$ \\
\hline a & 26 & 400 \\
c & 31 & 835 \\
\hline
\end{tabular}

Fig. 4. Example of SHG-intensity of a monolayer of $4 \mathbf{c}$ deposited on both sides of a hydrophobic glass slide ( $\mathbf{m}$ ) and best fit theoretical curve $(-)$ as a function of the angle of incidence $\theta$ as well as data obtained by SHG for different monolayers of $\mathbf{4 c}$. The signals measured show the homogeneity of LB films on both sides of the glass slide.

Aggregation within polyene monolayers at the air-water interface can be determined by reflection spectroscopy using light polarized vertical (s) or parallel (p) to the incidence plane. ${ }^{[19,20]}$ If s-polarized light is applied, the longest-wavelength band in the reflection spectra of monolayers of $4 \mathrm{c}$ on pure water is shifted hypsochromically with respect to the band which dominates the reflection spectra obtained under p-polarization (Fig. 5). This has to be attributed to the formation of $\mathrm{H}$-aggregates of polyenes $4 \mathrm{c}$ which are not observed using p-polarized light. The degree of aggregation of polyenes

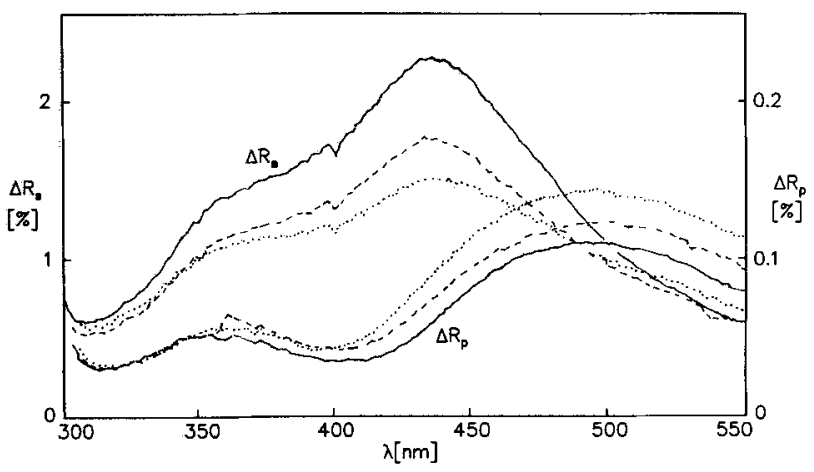

Fig. 5. Reflection spectra of monolayers of $4 \mathbf{c}$ under oblique incidence $\left(45^{\circ}\right)$ on pure water $\left(20^{\circ} \mathrm{C}, 15 \mathrm{mN} / \mathrm{m}\right)$. Each pair of curves was recorded after an identical procedure of spreading and compression. $\Delta R$ is the enhanced reflectivity due to the presence of the monolayer [19].

within these pure monolayers was not controllable, as inferred from the varying intensities of the respective bands in Fig. 5.

\section{Experimental}

Mono- and multilayers: The compounds were spread from dichloromethane solutions $\left(c=7 \cdot 10^{-4}\right.$ to $\left.1.4 \cdot 10^{-3} \mathrm{~mol} / \mathrm{l}\right)$ on a pure (distilled and Millipore purified) water subphase and the pressure-area diagrams were recorded using a Lauda Langmuir film balance. The LB layers were prepared with a Lauda Langmuir film balance at a transfer pressure of $20 \mathrm{mN} / \mathrm{m}$. Glass and quartz glass slides were purified with alkaline hydrogen peroxide solution and then hydrophobized with dichlorodimethylsilane in chloroform solution.

Nonlinear optics: Angle-dependent SHG was measured with apparatus described previously ${ }^{[21]}$, by excitation with a Nd-YAG laser (p-p-polarization). As standard, a quartz crystal with $d_{11}=1.2 \cdot 10^{-9}$ esu was used. For all calculations (formalism see [21]; estimated refractive index and film thickness: $n(1064 \mathrm{~nm})=1.5, n(532 \mathrm{~nm})=1.8 ; d=1.5 \mathrm{~nm})$ a nonlinear polarization parallel to the polyene axis was assumed.

Received: March 5, 1992 [AM-C 144] Final version: April 13, 1992

[1] J.-M. Lehn, Angew. Chem. 1988, 100,91-116; Angew. Chem. Int. Ed. Engl. 1988, 27, 89-114.

[2] J. Simon, J. J. André, A. Skoulios, Nouv, J. Chim. 1986, 10, 295-311.

[3] a) R. W. Munn, Chem. Br. 1984, 20, 518-524. b) P. Day, Chem. Br. 1990 , $26,52-54$.

[4] J. Simon, F. Tournilhac, J. J. André, New J. Chem. 1987, 11, 383-399.

[5] a) F. Effenberger, H. Schlosser, P. Bäuerle, S. Maier, H. Port, H. C. Wolf, Angew. Chem. 1988, 100, 274-277; Angew. Chem. Int. Ed. Engl. 1988, 27, 281-284. b) F. Effenberger, H. C. Wolf, New J. Chem. 1991, 15, 117-123. c) B. Heine, E. Sigmund, S. Maier, H. Port, H. C. Wolf, F. Effenberger, H. Schlosser, J. Mol. Electron. 1990, 6, 51-60.

[6] A. Slama-Schwok, M. Blanchard-Desce, J.-M. Lehn, J. Phys. Chem. 1990 94, 3894-3902.

[7] G. L. Gaines, Insoluble Monolayers at Liquid-Gas Interfaces, Interscience Publishers, New York 1966.

[8] a) J. Zyss, D. S. Chemla, Nonlinear Optical Properties of Organic Molecules and Crystals, Academic Press, Orlando 1986, b) D. J. Williams, Nonlinear Optical Properties of Organic and Polymeric Materials, ACS 233, ACS, Washington DC 1983. 
[9] G. J. Kavarnos, N. J. Turro, Chem. Rev. 1986, 86, 401-449.

[10] a) B. E. Maryanoff, A. B. Reitz, Chem. Rev. 1989, 89, 863-927. b) C.-P. Niesert, Dissertation, Univ. Stuttgart 1992.

[11] E. Clar, Polycyclic Hydrocarbons, Academic Press, New York 1964

[12] a) C. Erdelen, A. Laschewsky, H. Ringsdorf, J. Schneider, A. Schuster, Thin Solid Films 1989, 180, 153-166. b) M. Shimomura, K. Fujii, P. Karg, W. Frey, E. Sackmann, P. Meller, H. Ringsdorf, Jpn. J. Appl. Phys. 1988, 27, L1761-L1763. c) M. Shimomura, T. Kunitake, Thin Solid Films 1985, $132,243-248$.

[13] H. Möhwald, Angew. Chem. Adv. Mater. 1988, 100, 750-756.

[14] A. Milon, G. Wolff, G. Ourisson, Y. Nakatani, Helv. Chim. Acta 1986, 69, $12-24$

[15] N. Yamamoto, T. Ohnishi, M. Hatakeyama, H. Tsubomura, Bull. Chem. Soc. Jpn. 1978, 51, 3462-3465.

[16] G. Marowsky, R. Steinhoff, Opt. Lett. 1988, 13, 707-709.

[17] a) M. Blanchard-Desce, I. Ledoux, J-M. Lehn, J. Malthete, J. Zyss, J. Chem. Soc., Chem. Commun 1988, 737-739. b) F. Kajzar, I. Ledoux, Thin Solid Films 1989, 179, 359-367.

[18] a) J. O. Morley, V. J. Docherty, D. Pugh, J. Chem. Soc., Perkin Trans.II 1987, $1351-1355$. b) D. Q. Li, M. A. Ratner, T. J. Marks, J. Am. Chem. Soc. 1988, 110, 1707-1715.

[19] a) M. Orrit, D. Möbius, U. Lehmann, H. Meyer, J. Chem. Phys. 1986, 85, 4966-4979. b) D. Möbius, M. Orrit, H. Grüniger, H. Meyer, Thin Solid Films 1985, 132, 41-53.

[20] D. Möbius in Langmuir-Blodgett-Films (Ed.: G. Roberts), Plenum Press, New York 1990, p. 223

[21] a) C. Bubeck, A. Laschewsky, D. Lupo, D. Neher, P. Ottenbreit, W. Paulus, W. Prass, H. Ringsdorf, G. Wegner, Adv. Mater. 1991, 3, 54-58. b) D. Neher, Dissertation, Univ. Mainz, 1990.

[22] F. Effenberger, H. Schlosser, Synthesis 1990, 1085-1094.

[23] A. Nürrenbach, J. Paust, H. Pommer, J. Schneider, B. Schulz, Liebigs Ann. Chem. 1977, 1146-1159.

[24] A. R. Katritzky, B. Ternai, J. Chem. Soc. B, Phys. Org. 1966, 631-632.

[25] A. Wegmann, B. Tieke, I. Pfeiffer, B. Hilti, J. Chem. Soc, Chem. Commun. 1989, 586-588

[26] F. Effenberger, P. Meller, H. Ringsdorf, H. Schlosser, Adv. Mater. 1991 , $3,555-558$.

\section{Superconductor Thin Films: In Situ X-Ray Study on the Reaction of Hydrogen with Epitaxial $\mathrm{YBa}_{2} \mathrm{Cu}_{3} \mathrm{O}_{7}$ Layers**}

\author{
By Werner Paulus, Ralph Börner, Robert Schöllhorn," \\ Jürgen Schubert, Wilhelm Zander, Jeffrey Erxmaier, \\ and Alois Weidinger
}

Thin-layer systems represent a particular class of materials of increasing importance in various fields of application (optical components, superconducting junctions, photoelectric cells, quantum wells etc.). They are characterized by a strong correlation between form and function: their specific physical properties are influenced by the morphology and dimen-

[*] Prof. R. Schöllhorn, Dr. W. Paulus [ $\left.{ }^{+}\right]$, R. Börner Institut für Anorganische und Analytische Chemie, Technische Universität Berlin

Strasse des 17. Juni 135, 1000 Berlin 12 (FRG)

Dr. J. Schubert, Dr. W. Zander

Institut für Schicht- und Ionentechnik

Kernforschungszentrum Jülich, W-5170 Jülich (FRG)

Dr. J. Erxmaier, Dr. A. Weidinger

Hahn-Meitner Institut, 1000 Berlin 39 (FRG)

${ }^{+}$I Present adress: CEA-CNRS, Saclay, Lab. Léon Brillouin, F-91191 Gifsur-Yvette, France

[**] Support by the Bundesminister für Forschung und Technologie is gratefu]ly acknowledged by W. P., R. B. and R. S. [AMC 153] sional restrictions in the nanometer range. Interesting properties - differing from those of the bulk material-should also be expected in terms of chemical reactivity, particularly for epitaxially grown films and superlattices. We recently started systematic investigations on chemical reactions of thin-layer materials and report here on an in situ X-ray study of the reaction of molecular hydrogen with superconducting epitaxial $\mathrm{YBa}_{2} \mathrm{Cu}_{3} \mathrm{O}_{7}$ films which led to the detection of an unusual type of reaction mechanism.

High-temperature superconductors of the oxocuprate type are p-type metals (holes on oxygen and/or transitional metal) and their critical temperatures $T_{\mathrm{c}}$ have been shown to be strongly correlated with the hole concentration which can be varied by (i) isomorphic substitution of cationic lattice constituents and (ii) by variation of the oxygen stoichiometry, via thermal processes. ${ }^{[1]}$

The correlation between hole concentration and critical temperature is generally characterized by a maximum $T_{\mathrm{c}}$ value at a specific hole concentration. A third interesting model for the control of $T_{\mathrm{c}}$ via hole concentration change can be based on the reaction with hydrogen, since the insertion of $\mathrm{H}$ should be equivalent to the extinction of a corresponding amount of holes. The reversible formation of hydrogen bronzes from metal oxides $\mathrm{MO}_{n}$ via electrochemical electron/proton transfer (Eq. 1) or by direct hydrogen intercalation and the consequent modification of physical properties of the pristine solids are well known. ${ }^{[2]}$

$$
x \mathrm{H}^{\oplus}+\mathrm{xe}^{\ominus}+\mathrm{MO}_{n} \rightleftarrows \mathrm{H}_{x} \mathrm{MO}_{n}
$$

Hydrogen intercalation in polycrystalline $\mathrm{YBa}_{2} \mathrm{Cu}_{3} \mathrm{O}_{7}$ has been reported by several groups; ${ }^{[3]}$ changes in lattice parameters were found to be close to the error limit, however, and $T_{\mathrm{c}}$ onset temperatures were not affected after reaction with hydrogen, although a strong broadening of the transition and a decrease in volume susceptibility was noted. Therefore, the results on bulk material remain inconclusive. In order to profit from the single-crystal-like highly ordered state and the minor diffusion length perpendicular to the layer plane we decided to perform an investigation of hydrogen intercalation in epitaxially grown $\mathrm{YBa}_{2} \mathrm{Cu}_{3} \mathrm{O}_{7}$ thin films.

Thin films of $c$-axis oriented $\mathrm{YBa}_{2} \mathrm{Cu}_{3} \mathrm{O}_{7}$ on (100) $\mathrm{SrTiO}_{3}$ single-crystal substrates (thickness $4000 \AA$ ) were prepared by the laser ablation technique. ${ }^{[4]}$ The isothermal and isobaric reaction of the thin films with hydrogen and the simultaneous recording of $\mathrm{X}$-ray data was performed in situ on a Siemens D 500 powder diffractometer $(\theta / 2 \theta$ mode, primary monochromator) equipped with a low-temperature camera (PAAR LTK-10) at $460 \mathrm{~K}$ in a pure hydrogen atmosphere at a constant pressure of 100 mbar. X-ray patterns $\left(\mathrm{Cu}-\mathrm{K}_{\alpha 1}\right)$ were recorded with a fast position sensitive detector (Braun $\mathrm{M} 503$ ), a time resolution of $12 \mathrm{~min}$ per pattern and an angular scan range of $5^{\circ}$ to $110^{\circ}(2 \theta)$. The total number of patterns per experiment was of the order of 200 to 250 . The change in superconducting properties was checked by resistivity measurements (four probe technique) and indepen- 